TITLE:

\title{
Functional and expressional analyses of apple FLC-like in relation to dormancy progress and flower bud development.
}

\section{$\operatorname{AUTHOR}(S)$ :}

Nishiyama, Soichiro; Matsushita, Miwako Cecile; Yamane, Hisayo; Honda, Chikako; Okada, Kazuma; Tamada, Yosuke; Moriya, Shigeki; Tao, Ryutaro

\section{CITATION:}

Nishiyama, Soichiro ...[et al]. Functional and expressional analyses of apple FLC-like in relation to dormancy progress and flower bud development.. Tree physiology 2021, 41(4): 562-570

\section{ISSUE DATE:}

2021-04

URL:

http://hdl.handle.net/2433/263150

\section{RIGHT:}

This is a pre-copyedited, author-produced PDF of an article accepted for publication in 'Tree physiology' following peer review. The version of record "Nishiyama S, Matsushita MC, Yamane H, Honda C, Okada K, Tamada Y, Moriya S, Tao R; unctional and expressional analyses of apple FLC-like in relation to dormancy progress and flower bud development.Tree Physiology, 41 (4) 562-570" is available online at: https://doi.org/10.1093/treephys/tpz111; The fulltext file will be made open to the public on 14 November 2020 in accordance with publisher's 'Terms and Conditions for Self-Archiving'.; This is not the published version. Please cite only the published version. この論文は出版社版でありま せん。引用の際には出版社版をご確認ご利用ください。 
1 Functional and expressional analyses of apple FLC-like in relation to dormancy progress and

2 flower bud development

3

4 Soichiro Nishiyama ${ }^{1,6}$, Miwako Cecile Matsushita ${ }^{1,6}$, Hisayo Yamane ${ }^{1}$, Chikako Honda ${ }^{2}$, Kazuma

$5 \quad$ Okada $^{3}$, Yosuke Tamada ${ }^{4,5}$, Shigeki Moriya ${ }^{3}$, Ryutaro Tao ${ }^{1}$

$6 \quad{ }^{1}$ Graduate School of Agriculture, Kyoto University, Sakyo-Ku, Kyoto 606-8502, Japan

$7 \quad{ }^{2}$ Graduate School of Agricultural and Life Science, The University of Tokyo, Midori-Cho, Nishitokyo,

8 Tokyo 188-0002, Japan

$9 \quad{ }^{3}$ Apple Research Station, Institute of Fruit Tree and Tea Science, NARO, Morioka 020-0123, Japan

$10 \quad{ }^{4}$ National Institute for Basic Biology, Okazaki 444-8585, Japan

$11{ }^{5}$ School of Life Science, Sokendai, Okazaki 444-8585, Japan

$12 \quad{ }^{6}$ These authors contributed equally

13 Corresponding author: Hisayo Yamane (hyamane@kais.kyoto-u.ac.jp) (Tel: +81-75-753-6052)

14

15 Running head: Growth inhibiting function of apple FLC-like

16

17 


\section{Abstract}

We previously identified the FLOWERING LOCUS C (FLC)-like gene, a MADS-box transcription factor gene that belongs to Arabidopsis thaliana FLC clade, in apple (Malus x domestica), and its expression in dormant flower buds is positively correlated with cumulative cold exposure. To elucidate the role of the MdFLC-like in the dormancy process and flower development, we first characterized the phenotypes of MdFLC-like overexpressing lines with the Arabidopsis Columbia-0 background. The overexpression of MdFLC-like significantly delayed the bolting date and reduced the plant size, but it did not significantly affect the number of rosette leaves or flower organ formation. Thus, MdFLC-like may affect vegetative growth and development rather than flowering when expressed in Arabidopsis, which is not like Arabidopsis FLC that affects development of flowering. We compared seasonal expression patterns of MdFLC-like in low-chill 'Anna' and high-chill 'Fuji' and 'Tsugaru' apples collected from trees grown in a cold winter region in temperate zone, and found an earlier upregulation in 'Anna' compared with 'Fuji' and 'Tsugaru'. Expression patterns were also compared in relation to developmental changes in the flower primordia during the chilling accumulation period. Overall, MdFLC-like was progressively up-regulated during flower primordia differentiation and development in autumn to early winter, and reached a maximum expression level at around the same time as the genotype-dependent chilling requirements were fulfilled in high-chill cultivars. Thus, we hypothesize MdFLC-like may be up-regulated in response to cold exposure and flower primordia development during the progress of endodormancy. Our study also suggests MdFLC-like may have a 
38 is low and unfavorable for rapid bud outgrowth.

39

40 Keywords; bud dormancy, chilling requirement, FLC, flower development, MADS-box transcription

41 factor, Malus $\times$ domestica

42

43 


\section{Introduction}

Perennial woody plant species native to temperate zones modulate their growth to correspond with seasonal environmental changes and often suspend growth during the winter. This process is known as dormancy and is considered an adaptive process that enables plants to survive environmental stresses, such as low temperature. Lang (1987) and Lang et al. (1987) defined plant dormancy as "the temporary suspension of visible growth of any plant structure containing a meristem" and classified the fruit tree bud dormancy states as paradormancy, endodormancy, and ecodormancy. Both paradormancy and endodormancy are states induced by the perception of environmental or endogenous signaling cues, but they differ in whether they originate solely from meristem-containing tissue (endodormant) or from structures distinct from that undergoing dormancy (paradormant). A certain specific amount of chilling exposure is critical for inducing the shift from endodormancy to ecodormancy, known as the "chilling requirement for endodormancy completion and release". Ecodormancy is a state brought about by a limitation in growth-promoting factors, such as warm conditions and the availability of water and nutrients. Whether buds are endodormant or ecodormant has been determined according to the competency of bud break, which is often based on the increase and decrease in the mean-time until bud break or in bud break percentage under forcing conditions. For example, genotype-dependent chilling requirements for endodormancy release are often considered satisfied at a specific sampling time point, if the bud break frequency increased over a threshold (often 50\%) under forcing conditions (Bielenberg et al. 2015, Kitamura et al. 2018).

63 Although Lang's definition has been widely adopted by horticultural researchers, recently 
64 accumulated data suggest that this terminology may need to be revised (Cooke et al. 2012, Considine

65

66

67 and Considine 2016, Yamane, 2014). Apple (Malus $\times$ domestica), an economically important fruit crops, has adapted to the cool climate of temperate regions. In typical apple cultivars, flower meristem initiation occurs in early summer after terminal bud set (Kotoda et al., 2010). Then, terminal flower buds enter a dormant state in winter until blooming in spring. Typical characteristics of apple dormancy are that dormancy is induced and released in response to low temperature independent of photoperiod (Heide and Prestrud 2005). To date, the molecular mechanism underlying apple dormancy has been studied with a focus on specific gene(s) and gene network expression level changes (Falavigna et al. 2019, Kumar et al. 2016, Porto et al. 2015, Saito et al. 2017, Wang et al. 1991, Wisniewski et al. 2015) as well as the genetic control of bud break and blooming date (Allard et al. 2016, van Dyk et al. 2010, Celton et al. 2011, Miotto et al. 2019, Trainin et al. 2016, Urrestarazu et al. 2017).

We previously conducted RNA-sequencing (RNA-Seq) studies and identified a limited number of genes that were strongly associated with chill-unit accumulation under natural and coldtreated conditions using a strict candidate-gene selection strategy (Takeuchi et al. 2018). A highly significantly correlated gene was a MADS-box gene (hereafter MdFLC-like; MD09G1009100) found in a clade that included FLOWERING LOCUS C (FLC) and MADS AFFECTING FLOWERING (MAF) genes. Arabidopsis FLC represses the transcription of floral integrator genes, such as FT and SOC1, thus acting as a floral repressor to delay the development of floral buds and bolting, resulting in the increased number of leaves in flowering and bolting (Searle et al. 2006). In Arabidopsis, all the 
genes in the FLC clade have the ability to repress the flowering pathway (Ratcliffe et al. 2001, Gu et al. 2013). Also, an FLC ortholog of Arabis alpine, PEP1, functions in the return to vegetative development after flowering, implying the significance of the FLC orthologs in the plant perennial life cycle (Wang et al. 2009). Moreover, the involvement of MAF3-like homologs in dehydration-induced endodormancy regulation was reported in leafy spurge (Dogramaci et al. 2014). apple flower buds (Porto et al. 2015, Takeuchi et al. 2018). In contrast, although Arabidopsis FLC is up-regulated in response to endogenous factors and environmental cues such as low temperatures (Aikawa et al. 2010; Gu et al. 2013), it is down-regulated by prolonged cold during the vernalization process (Michaels and Amasino, 1999). The up-regulation of the FLC-like gene's expression concomitant to cumulative low temperature exposure has been found not only in apple, but also in other Rosaceae perennial species such as Prunus pseudocerasus (Zhu et al. 2015) and Taihangia rupestris (Du et al. 2008). Consequently, FLC-like genes may have unique functions in the perennial life cycles in Rosaceae; however, the biological function of MdFLC-like has yet to be investigated. Here, we conducted a functional characterization of MdFLC-like using Arabidopsis overexpression lines to determine whether MdFLC-like is functionally similar to Arabidopsis FLC. We also compared gene expression patterns across three apple cultivars, 'Anna', 'Fuji', and 'Tsugaru', which have different dormancy behaviors, to analyze the expression changes of MdFLC-like in relation to chilling requirement fulfillment, dormancy progress during endodormancy, the transition from endodormancy 
104 were also compared in relation to developmental changes in the flower primordia during the chilling

105 accumulation period.

Materials and Methods

MdFLC-like-specific primers were designed based on the published sequences

(MD09G1009100; Daccord et al. 2017) as follows: mdFLC1-pGWB2-for (5'-

111 [CACGgGgACtCTAG]AATGGGGCGAGGGAAGGTG-3’) and mdFLC1-pGWB2-rev (5’-

112 [GATCGGGGAAATTCGAGCT]CTTCAAAACAATTGTAGTATGGTGGC-3'). The full-length

113 coding sequence of MdFLC1 was amplified from 'Fuji' dormant buds cDNAs using the PrimeStar

114 GXL (TaKaRa) and the primers listed above. Amplified fragments were cloned into the XbaI- and

115 SacI-digested pGWB2 vector (Nakagawa et al. 2007), placing the gene under the Cauliflower mosaic

116 virus 35S promoter, using an In-Fusion HD cloning kit (TaKaRa). The sequences between brackets in

117 the primers listed above were used for the recombination. The resultant 35S:MdFLC-like plasmid was

118 verified by Sanger-sequencing and then transformed into Agrobacterium tumefaciens strain EHA105

119 by electroporation. 
124 photoperiod conditions (16-h light/8-h dark photoperiod) at $22{ }^{\circ} \mathrm{C}$. We also confirmed the

125 transformation by the PCR amplification of MdFLC-like. The selected plants were transplanted into a

126 standard soil mixture soon after cotyledon expansion, and grown in a wrapped pot to maintain a high-

127 humidity level for the initial 3 days. Plants were then grown under a long photoperiod conditions.

128 Bolting date, flowering date, and the number of rosette leaves at bolting and flowering were recorded for each transformed plant. winter but not extreme cold subarctic and boreal zone, which is suitable region for apple production.

141 Utah model (Richardson et al. 1974), which is calculated based on the hourly highest temperatures 
144 each sampling date, flower buds dissected from collected shoots were immediately frozen in liquid

145 nitrogen and stored at $-80^{\circ} \mathrm{C}$ until used. To analyze the expression changes of $M d F L C$-like in response

146 to warm temperatures, 40-cm shoots of 'Fuji' and 'Anna' collected at the $1200 \mathrm{CU}$ sampling point

147 were incubated under forcing conditions $\left(22^{\circ} \mathrm{C}\right.$ and a $16-\mathrm{h}$ light/8-h dark photoperiod). The terminal

148 flower buds were then sampled just before bud burst occurred and frozen in liquid nitrogen and stored

149 at $-80^{\circ} \mathrm{C}$ until used. 
164 (Thermo Fisher Scientific) in accordance with the manufacturer's instructions. Then, $600 \mathrm{ng}$ of total RNA was reverse-transcribed using the ReverTra Ace ${ }^{\circledR}$ qPCR RT Master Mix with gDNA Remover

166 (Toyobo). Quantitative RT-PCR (qPCR) was conducted using LightCycler 480 (Roche) and THUNDERBIRD® SYBR qPCR Mix (Toyobo). The expression level of MdFLC-like was analyzed using primers FLC_qPCR_for (5'-GGAGGAGCGGGCTTATCAAG-3') and FLC_qPCR_rev (5'TTGGCGGAGAAGATGACGAG-3'). qPCR for MdFLC-like was performed under the following conditions: $95^{\circ} \mathrm{C}$ for $5 \mathrm{~min}$ followed by 40 cycles of $95^{\circ} \mathrm{C}$ for $5 \mathrm{~s}$ and $60^{\circ} \mathrm{C}$ for $1 \mathrm{~min}$. Gene-specific amplification was confirmed using a melting curve. SAND was used as the reference gene as described previously (Imai et al. 2014). Three to five independent samples (flower buds) were used as biological replicates with one technical replicate each for each measurement. 


\section{Results}

Functional characterization of MdFLC-like in transgenic Arabidopsis

To assess the functional conservation between MdFLC-like and Arabidopsis FLC in 
204 was observed in the shoots at $600 \mathrm{CU}$ or less, except 'Tsugaru' which showed a $25 \%$ bud burst at 0

205 CU. Bud burst rate was greater than $50 \%$ at 986 and 754 CU for 'Fuji' and 'Tsugaru', respectively

206 (Figure 3). The days required for bud burst under forcing conditions decreased with CU accumulation

207 in all three cultivars analyzed (Figure 3).

208

Expression changes of MdFLC-like during chilling requirement fulfillment and in response to warm especially in 'Fuji’ and 'Tsugaru’. 
224 observed both in 'Anna' and 'Fuji', regardless of the difference in the amounts of chilling requirement.

Comparative morphological observation of flower primordia at 0, 400, and 800 CU between 'Fuji'

and 'Anna'

Among the observed flower buds at 0 and $400 \mathrm{CU}$, those of 'Anna' had larger central and

'Fuji' under our experimental conditions.

\section{Discussion}

MdFLC-like inhibited vegetative growth in Arabidopsis

241 increase in the number of rosette leaves at bolting (Michaels and Amasino 1999). Similary, 
244 smaller than the controls. These results implied that MdFLC-like is involved in the inhibition of

245 vegetative growth rather than flowering as like Arabidopsis FLC. Deng et al. (2011) raised the

246 possibility that Arabidopsis FLC may regulate not only flowering but also other developmental

247 pathways by changing binding partners. Indeed, our amino acid sequence alignment indicated that

248 some amino acid sequence set in the k-box region is deleted whereas those in the MADS-box domain

249 are highly conserved in MdFLC-like compared to other FLC homologs of apple (Supplementary Fig.

250 1). This suggests that MdFLC-like protein may have an ability to form different protein-protein

251 complexes from those of other FLC homologs. Further studies will be needed to clarify the mode-of-

252 action of the MdFLC-like functionality in apple. The study additionally showed that the

253 overexpression of MdFLC-like resulted in the rapid induction of secondary scapes, which may suggest

254 that MdFLC-like modulates the plant architecture possibly by affecting phytohormone levels.

255 Consequently, we hypothesize that MdFLC-like affects vegetative growth rather than reproductive

256 development in Arabidopsis and may act as a general growth regulator.

257

MdFLC-like was highly expressed when genotype-dependent chilling requirement was fulfilled

We first confirmed the very small amount of chilling requirement in low-chill ‘Anna' based

on bud burst behavior under forcing conditions during seasonal chilling accumulation. 'Anna' is an

261 Israeli low-chill cultivar that needs $200-300 \mathrm{~h}$ below $7.2^{\circ} \mathrm{C}$ to break bud dormancy, which is estimated 
264 cultivars in Japan, although exact amount of chilling requirements for 'Anna' grown in Morioka, Japan,

265 appeared to be even lower than 200 CU. The chilling requirements of 'Fuji' and 'Tsugaru' were

266 estimated to be approximately $800-1,000 \mathrm{CU}$, which is consistent with previous studies reporting that

267 the chilling requirement for a greater than $50 \%$ bud break under forcing conditions for 'Fuji' grown in

268 Nagano Prefecture, Japan was 800 CU (Takeuchi et al. 2018).

Seasonal expression patterns of MdFLC-like were positively correlated with low temperature accumulations in apple cultivars having different chilling requirements in our 2-year's experiment, which is consistent with our previous findings (Takeuchi et al., 2018). Even under the fluctuating climatic conditions, MdFLC-like's expression appeared to peak near the time when the cultivar-dependent chilling requirement was fulfilled especially in high-chill cultivars, suggesting the robust control of expression during endodormancy until chilling requirement fulfillment, which may occur through the sensing of chilling accumulation. In addition, MdFLC-like was down-regulated by warm temperature (Figure 5). In Arabidopsis halleri, seasonal changes in FLC expression are system. 
284 the terminal bud break is repressed (Kurokura et al., 2013). Thus, we hypothesize that differential expression of MdFLC-like between low-chill and high-chill cultivars before chilling requirement fulfillment may reflect differences in not only temperature response but also internal structures of flower buds. To test this hypothesis, we compared the morphological changes in flower primordia between low-chill 'Anna' and high-chill 'Fuji' at 0-800 CU. Interestingly, the obvious suspension of flower primordia development has been observed in 'Anna' but not in 'Fuji' during chilling accumulation until the late stage of endodormancy. Central and lateral flower sizes of 'Fuji' continue to increase from 0 to $800 \mathrm{CU}$ when the flower size became comparable to that of 'Anna'. the involvement of flower development in regulatory mechanism of MdFLC-like expression. 
304 (Reinoso et al. 2002). However, the progress of flower primordia development in low-chill cultivars

305 in comparison with high-chill cultivars appeared to be different between apple (this study) and Prunus

306 fruit trees. Our microscopic observations suggested that flower differentiation and development is

307 rather advanced in low-chill 'Anna' compared to high-chill 'Fuji' at 0 and 400 CU. Faster and more rapid flower differentiation in 'Anna' in comparison with high-chill cultivars was also reported in 'Anna' trees grown in warm climate (Oukabli et al. 2003). The present study showed that flower differentiation in 'Anna' was also faster even in cold winter climate region in temperate zone. In contrast, floral differentiation progresses was slower in low-chill cultivars than in high-chill cultivars in Prunus species such as peach (Yamane et al. 2011), sweet cherry (P. avium) (Fadón et al. 2018), and Japanese apricot (P. mume) (Kitamura et al. 2016). One of the possibilities to explain the discrepancy between apple and Prunus is that they have different ability to respond to dormancy inductive environmental conditions. Typical apple cultivars do not respond to decreasing photoperiod to induce dormancy (Heide and Prestrud 2005), whereas Prunus fruit trees usually respond both decreasing

317 photoperiod and temperature to induce dormancy (Heide 2008). However, more comprehensive microscopic observation using other apple cultivars showing contrasting chilling requirement will be required to confirm the relationship between chilling requirement and flower development in apple. 
324 possible role of MdFLC-like in flower buds during winter could be prevention of unexpected bud

325 outgrowth during late endodormancy and early ecodormancy. MdFLC-like expression was down-

326 regulated in response to warm temperatures. High MdFLC-like expression level in ecodormant period

327 may, thus, contribute to the heat requirement for bud break of dormant buds. Decreased expression level of MdFLC-like in response to warm temperatures towards spring may lead to the actuation of the buds outgrowth competency in spring. For the phenological growth regulation of perennial plants, growth inhibition in winter could be systemically maintained by particular regulatory network. Expressions of the genes in a monophyletic FLC clade in Arabidopsis were known to be regulated by cold temperatures (Gu et al. 2013). Furthermore, this cold temperature-dependent regulation of FLC expression is known to be mediated by histone modifications of the FLC locus in Arabidopsis (Bastow et al. 2004). This study showed that MdFLC-like appeared to function as a growth regulator in response to cold and warm temperature and also to the flower primordia development. Biological significance of the upregulation of MdFLC-like during endodormancy progress and the functional characterization of MdFLC-like in Malus background would further highlight the significance of FLC homologs on the perennial life cycles of Rosaceae plants.

\section{Conclusions}


344 Rosid plants, with regards to the temperature sensitivity, although the directions of the expression

345 changes in response to chilling accumulation were opposite between Arabidopsis and Malus. The gene

346 expression was positively correlated with chilling accumulation in Malus and they were negatively

347 correlated in Arabidopsis. In addition, the MdFLC-like function in growth inhibition is different from

348 that of Brassicaceae FLC in flowering repression. Interestingly, the MdFLC-like expression appeared

349 to be robustly controlled under fluctuating environmental conditions and was highly associated with

350 the fulfillment of the chilling requirement in different apple genotypes. This suggested the involvement

351 of MdFLC-like in the regulatory system underlying the bud dormancy transition and flower

352 developmental regulation during winter. Consequently, we hypothesized that MdFLC-like has a role

353 in growth regulation of apple flower buds during late endodormancy and ecodormancy periods to

354 prevent bud outgrowth. The significance of this pathway in the dormancy process of apple should be

355 addressed in the future.

356

357

Acknowledgements

We thank Lesley Benyon, PhD, from Edanz Group (www.edanzediting.com/ac) for editing a draft of

this manuscript.

\section{Conflict of interest}

The authors declare that no competing interests exist. 


\section{Funding}

This study was supported by the Japan Society for the Promotion of Science (Grant-in-Aids

KAKENHI Nos. 26252005 to H. Y., $18 H 02198$ to H. Y. and Y. T., $18 H 04790$ to Y. T.)

\section{References}

Aikawa S, Kobayashi M, Satake A, Shimizu KK, Kudoh H (2010) Robust control of the seasonal expression of the Arabidopsis FLC gene in a fluctuating environment. PNAS 107:11632-11637.

Allard A, Legave JM, Martinez S, Kelner JJ, Bink MCAM, Di Guardo M, Di Pierro EA, Laurens F, van de Weg EW, Costes E (2016) Detecting QTLs and putative candidate genes involved in budbreak and flowering time in an apple multiparental population. J Exp Bot 67:2875-2888.

Bielenberg DG, Rauh B, Fan S, Gasic K, Abbott AG, Reighard GL, Okie WR, Wells CE (2015) requirement and bloom date in peach [Prunus persica (L.) Batsch]. PLoS ONE 10:e0139406. epigenetic silencing of FLC by histone methylation. Nature 427:164-167. 

192:378-92.

Considine MJ, Considine JA (2016) On the language and physiology of dormancy and quiescence in plants. J Exp Bot 67: 3189-3203.

Cooke JK, Eriksson ME, Junttila, O (2012) The dynamic nature of bud dormancy in trees: environmental control and molecular mechanisms. Plant Cell Env 35:1707-1728.

Daccord N, Celton J-M, Linsmith G, Becker C, Choisne N, Schijlen E, van de Geest H, Bianco L, Micheletti D, Velasco R, Di Pierro EA, Gouzy J, Rees DJG, Guérif P, Muranty H, Durel C-E, Laurens F, Lespinasse Y, Gaillard S, Aubourg S, Quesneville H, Weigel D, van de Weg E, Troggio M, Bucher E (2017) High-quality de novo assembly of the apple genome and methylome dynamics of early fruit development. Nat Genet 49:1099-1106. 108:6680-6685.

Doğramacı M, Horvath DP, Anderson JV (2014) Dehydration-induced endodormancy in crown buds of leafy spurge highlights involvement of MAF3-and RVE1-like homologs, and hormone signaling cross-talk. Plant Mol Biol 86:409-424.

Du X, Xiao Q, Zhao R, Wu F, Xu Q, Chong K, Meng Z (2008) TrMADS3, a new MADS-box gene, seasonal fluctuation in expression level. Dev Genes Evol 218:281-92. 
404

405

406

407

van Dyk MM, Soeker MK, Labuschagne IF, Rees DJG (2010) Identification of a major QTL for time of initial vegetative budbreak in apple (Malus x domestica Borkh.). Tree Genet Genomes 6:489502.

Fadón E, Rodrigo J, Herrero M (2018) Is there a specific starge to rest? Morphological changes in flower primordia in relation to endodormancy in sweet cherry (Prunus avium L.). Trees 32:1583-1594.

Falavigna VS, Guitton B, Costes E, Andres F (2019) I want to (Bud) break free: The potential role of $D A M$ and SVP-like genes in regulating dormancy cycle in temperate fruit trees. Front Plant Sci 9:1990

Gu X, Le C, Wang Y, Li Z, Jiang D, Wang Y, He Y (2013) Arabidopsis FLC clade members form flowering-repressor complexes coordinating responses to endogenous and environmental cues. Nat Commun 4:1947.

Heide OM. (2008) Interaction of photoperiod and temperature in the control of growth and dormancy of Prunus species. Sci Hort 115:309-314.

Heide OM, Prestrud AK (2005) Low temperature, but not photoperiod, controls growth cessation and dormancy induction and release in apple and pear. Tree Physiol 25:109-14.

Imai T, Ubi BE, Saito T, Moriguchi T (2014) Evaluation of reference genes for accurate normalization of gene expression for real time-quantitative PCR in Pyrus pyrifolia using different tissue samples and seasonal conditions. PLoS One 9:e86492.

Kawamoto T (2003) Use of a new adhesive film for the preparation of multi-purpose fresh-frozen 
Kitamura Y, Takeuchi T, Yamane H, Tao R (2016) Simultaneous down-regulation of DORMANCYASSOCIATED MADS-box6 and SOC1 during dormancy release in Japanese apricot (Prunus mume) flower buds. J Hort Sci Biotech 91:476-482 analysis and transcriptional profiling of MADS-box gene family identified DAM and FLC-like genes in apple (Malus x domestica). Sci Rep 6:20695. Rosaceae. J Exp Bot 64:4131-4141. 51: 561-575. 
that acts as a repressor of flowering. Plant Cell 11:949-56.

Miotto EV, Tessele C, Czermainski ABC, Porto DD, Falavigna VS, Sartor T, Cattani AM, Delatorre CA, de Alencar SA, da Silva-Jnior OB, Togawa RC, Costa MMC, Pappas Jr GJ, Grynberg P, de Oliveira PRD, Kvitschal MV, Denardi F, Buffon V, Revers LF (2019) Spring is coming: Genetic analyses of the bud break date locus reveal candidate genes from the cold perception pathway to dormancy release in apple (Malus × domestica Borkh.) Front. Plant Sci 10:33. T, Kimura T (2007) Development of series of gateway binary vectors, pGWBs, for realizing efficient construction of fusion genes for plant transformation. J Biosci Bioeng 104:34-41.

Oukabli A, Bartolini S, Viti R (2003) Anatomical and morphological study of apple (Malus $\times$ domestica Borkh.) flower buds growing under inadequate winter chilling. J Hort Sci Biotech 78:580-585. FLC-like genes. J Exp Bot 66:2659-2672. by an FLC homologue. Plant Physiol 126:122-32.

Reinoso H, Luna V, Pharis RP, Bottini R (2002) Dormancy in peach (Prunus persica) flower buds. V. Anatomy of bud development in relation to phenological stage. Can J Bot 80:656-663. 
and 'Elberta' peach trees. HortSci 9:331-332.

465

Saito T, Wang S, Ohkawa K, Ohara H, Ikeura H, Ogawa Y, Kondo S (2017) Lipid droplet-associated gene expression and chromatin remodelling in LIPASE 5-upstream region from beginning-to mid-endodormant bud in‘Fuji’apple. Plant Mol Biol 95:441-449

Searle I, He Y, Turck F, Vincent C, Fornara F, Kröber S, Amasino RA, Coupland G (2006) The transcription factor FLC confers a flowering response to vernalization by repressing meristem competence and systemic signaling in Arabidopsis. Genes Dev 20:898-912.

Takeuchi T, Matsushita MC, Nishiyama S, Yamane H, Banno K, Tao R (2018) RNA-sequencing analysis identifies genes associated with chilling-mediated rndodormancy release in apple. J Am Soc Hortic Sci 143:194-206.

Trainin T, Zohar M, Shimoni-Shor E, Doron-Faigenboim A, Bar-Ya'akov I, Hatib K, Sela N, Holland D, Isaacson T (2016) A unique haplotype found in apple accessions exhibiting early bud-break could serve as a marker for breeding apples with low chilling requirements. Mol Breed 36:158

Urrestarazu J, Muranty H, Denancé C, Leforestier D, Ravon E, Guyader A, Guisnel R, Feugey L, Aubourg S, Celton J-M, Daccord N, Dondini L, Gregori R, Lateur M, Houben P, Ordidge M, Paprstein F, Sedlak J, Nybom H, Garkava-Gustavsson L, Troggio M, Bianco L, Velasco R, Poncet C, Théron A, Moriya S, Bink MCAM, Laurens F, Tartarini S, Dure CE. (2017) Genomewide association mapping of flowering and ripening periods in apple. Front Plant Sci 8:1923

Wang R, Farrona S, Vincent C, Joecker A, Schoof H, Turck F, Alonso-Blanco C, Coupland G, Albani MC (2009) PEP1 regulates perennial flowering in Arabis alpina. Nature 459:423-427. 
484

485

486

487

488

489

490

491

492

493

494

495

496

497

498

499

500

Wang SY, Jiao HJ, Faust M (1991) Changes in superoxide dismutase activity during thidiazuroninduced lateral budbreak of apple. HortSci 26:171-173.

Wisniewski M, Norelli J, Artlip T (2015) Overexpression of a peach CBF gene in apple: a model for understanding the integration of growth, dormancy, and cold hardiness in woody plants. Front Plant Sci 6:85.

Yamane H (2014) Regulation of bud dormancy and bud break in Japanese apricot (Prunus mume Siebold \& Zucc.) and peach [Prunus persica (L.) Batsch]: A summary of recent studies. J Japan Soc Hort Sci 83:187-202.

Yamane H, Ooka T, Jotatsu H, Sasaki R, Tao R (2011) Expression analysis of PpDAM5 and PpDAM6 during flower bud development in peach (Prunus persica). Sci Hort 129:844-848.

Zhang X, Henriques R, Lin S-S, Niu Q-W, Chua N-H (2006) Agrobacterium-mediated transformation of Arabidopsis thaliana using the floral dip method. Nat Protoc 1:641-646.

Zhu Y, Li Y, Xin D, Chen W, Shao X, Wang Y, Guo W (2015) RNA-Seq-based transcriptome analysis of dormant flower buds of Chinese cherry (Prunus pseudocerasus). Gene 555:362-376. 
Figure 1. Characterization of MdFLC-like-overexpressing Arabidopsis. Bar plots of (A) the number of days to bolting; (B) number of days to flowering, (C) number of rosette leaves at bolting, (D) number of rosette leaves at flowering for 35S:MdFLC-like and wild type (WT) plants. In total, 10 independent transgenic lines were monitored for each genotype. Mean values are indicated as " $\mathrm{x}$ ". Significant differences were determined using a t-test, and p-values were designated.

Figure 2. Typical appearance of MdFLC-like-overexpressing Arabidopsis. (A, B) Left: wild type (WT), right: 35S:MdFLC-like; (C) WT; (D, E) 35S:MdFLC-like. Arrows indicate developed scapes.

Figure 3. Characterization of seasonal changes in the dormancy states of different apple cultivars.

513 Bars and lines indicate the bud burst rate and the average number of weeks required for the bud burst

514 under forcing conditions, respectively. At least five shoots were assessed at each sampling date. (A)

517 Figure 4. Expression patterns of MdFLC-like in apple terminal flower buds (A) in the 2016-2017 and (B) 2017-2018 seasons. Error bars indicate the standard errors for three to five biological replicates.

Figure 5. Effects of warm temperature on MdFLC-like expression in apple ecodormant flower buds. 
521 Shoots bearing flower buds collected at 1200CU (left) were treated with warm temperatures (right).

522 Error bars indicate the standard errors of three biological replicates.

523

524 Figure 6. Microscopic observations of flower meristem development in dormant apple buds during

525 dormancy. At least five flower buds were observed at each sampling, and representative tissue sections

526 are shown. (A) Overall picture of longitudinal sections of terminal flower bud; and (B) Enlarged

527 picture of central and lateral flower primordia of longitudinal sections of different terminal flower

528 buds collected at the same date as that in (A). All pictures in (B) were under the same scale.

530 Supplementary Figure 1. Amino acid sequence alignment of FLC homologs of Arabidopsis and

531 apple identified by Takeuchi et al., 2018. 
(A)

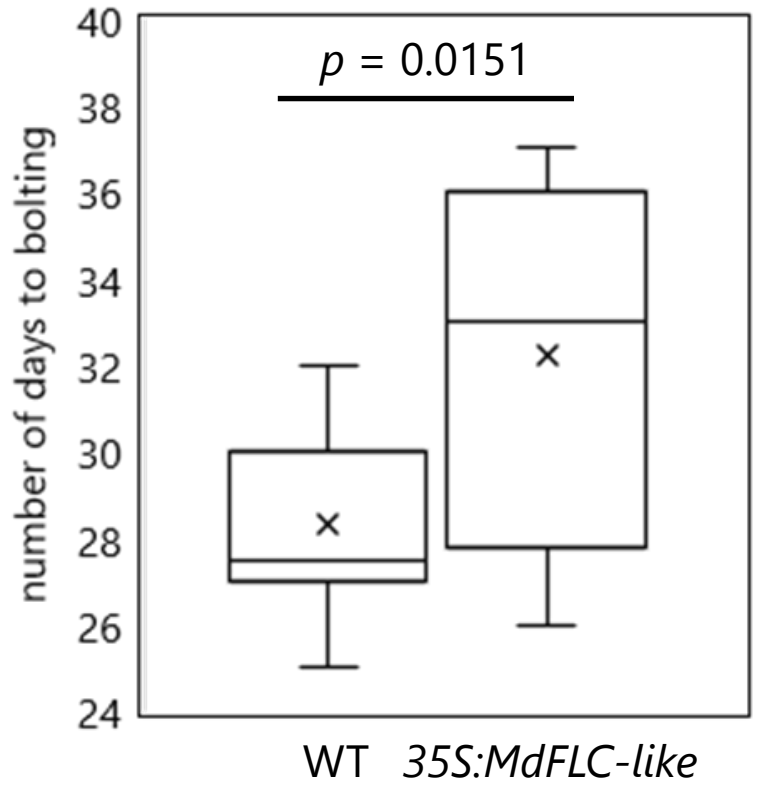

(C)

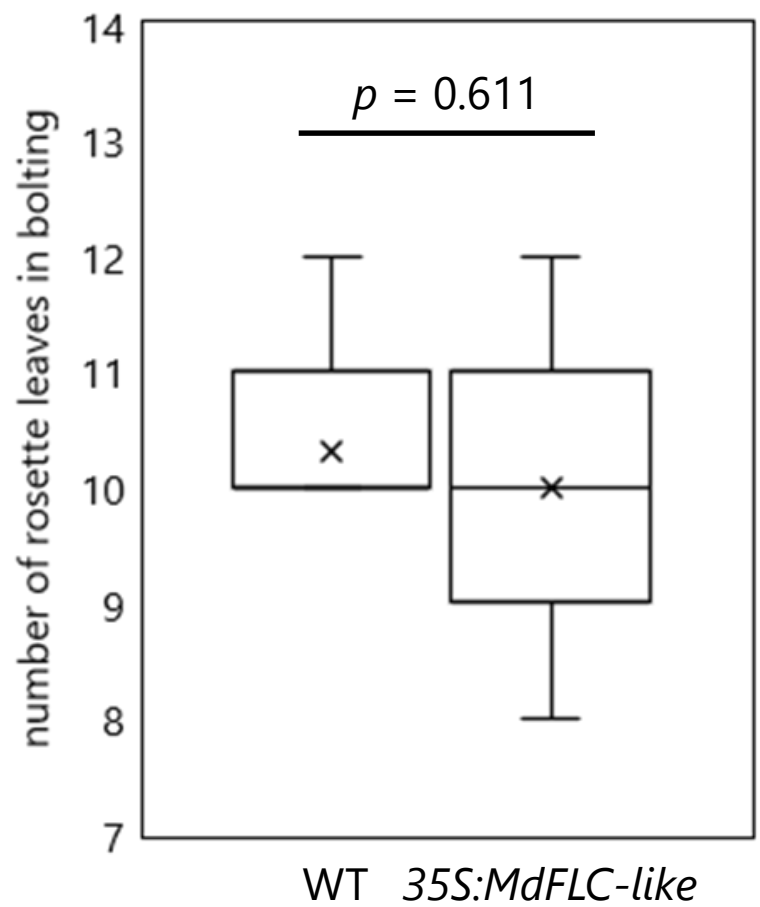

(B)

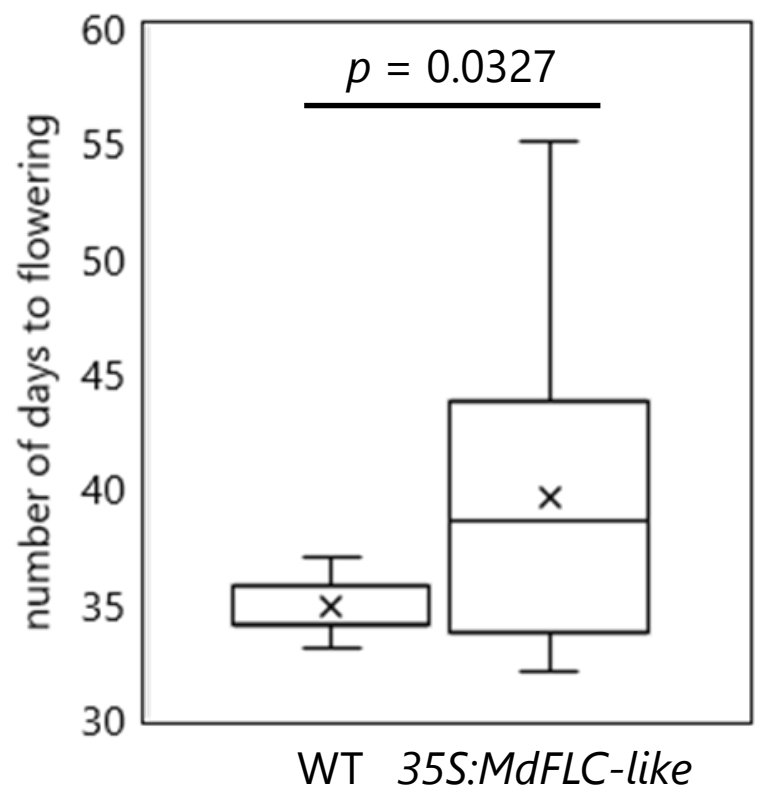

(D)

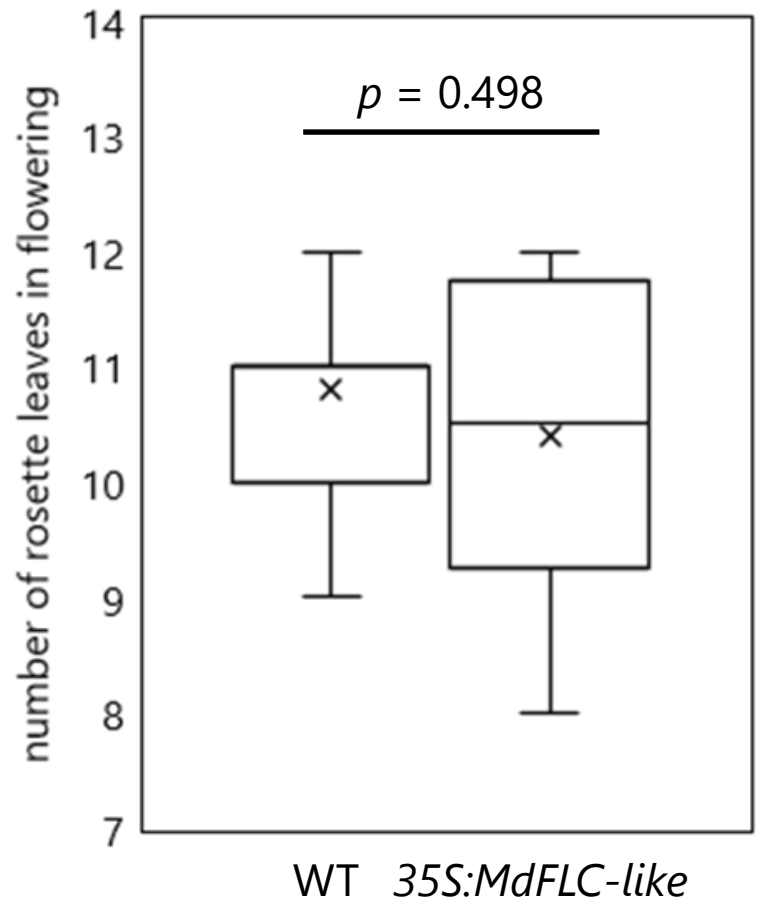




\section{A}

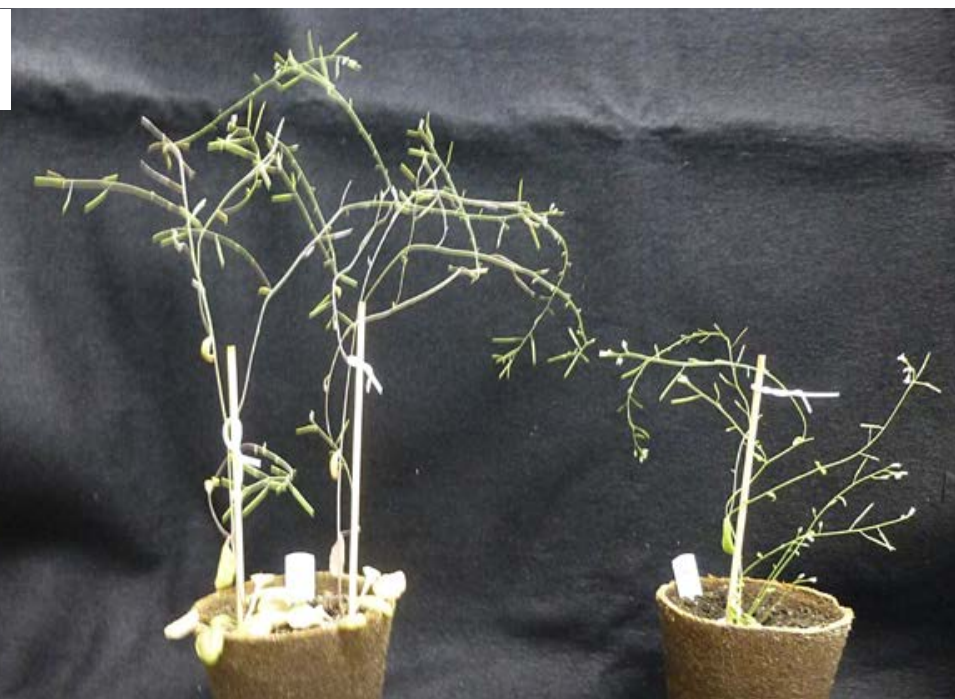

\section{B}
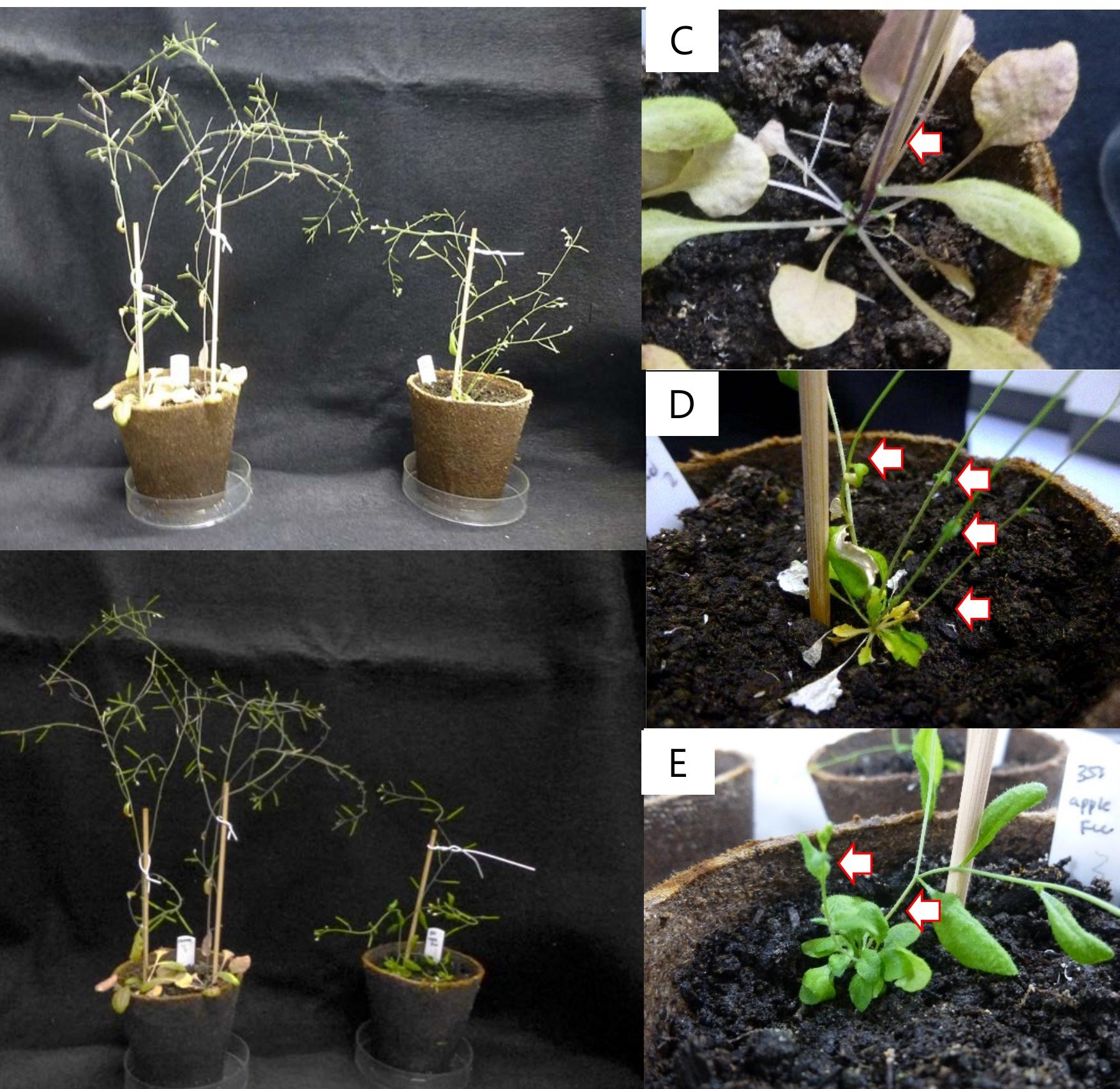
(A)

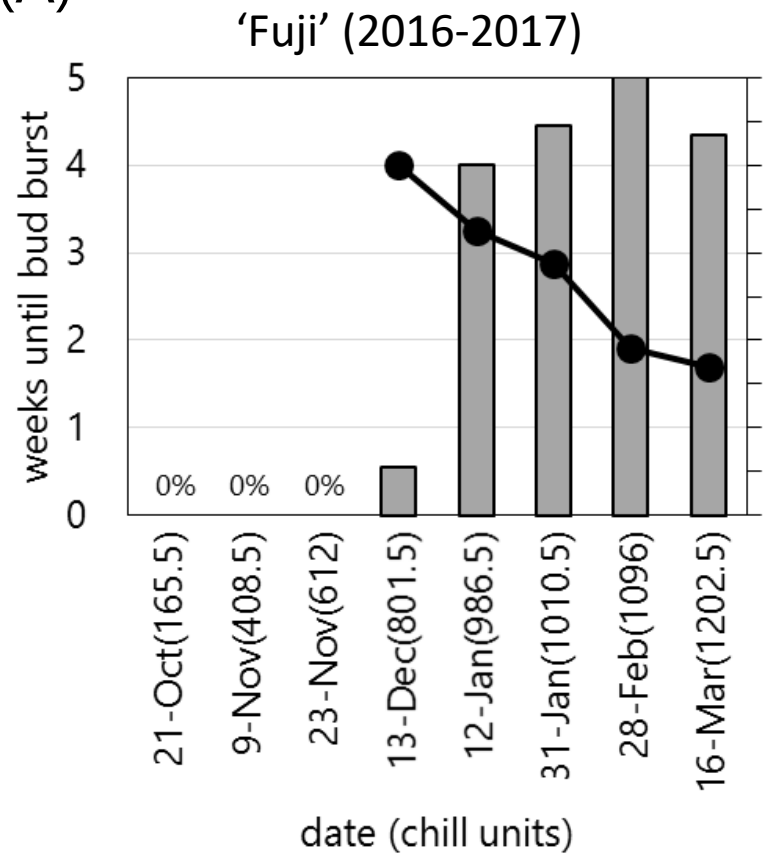

(C)

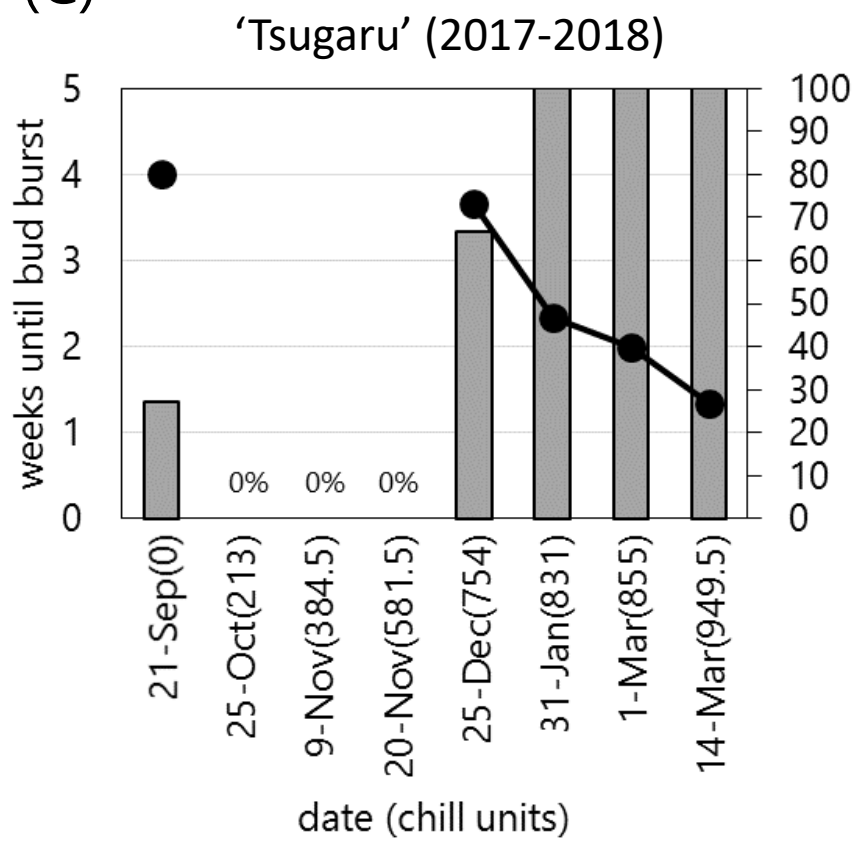

(B)

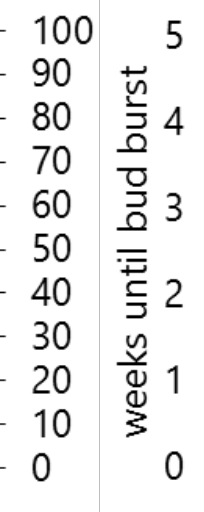

กิก สิ กิ

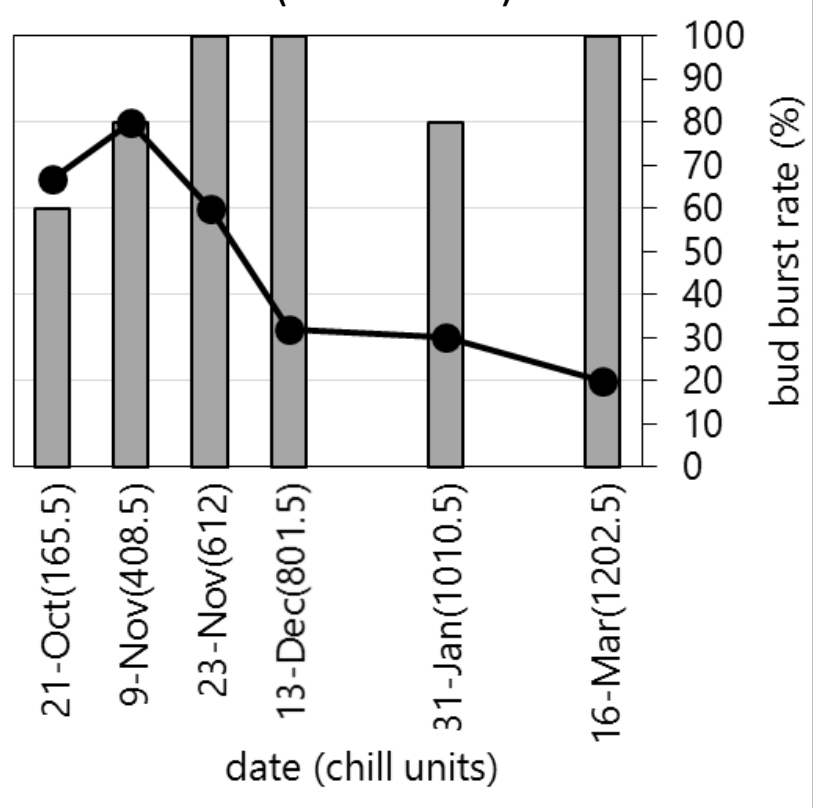

date (chill units)

'Anna' (2016-2017)

(D)

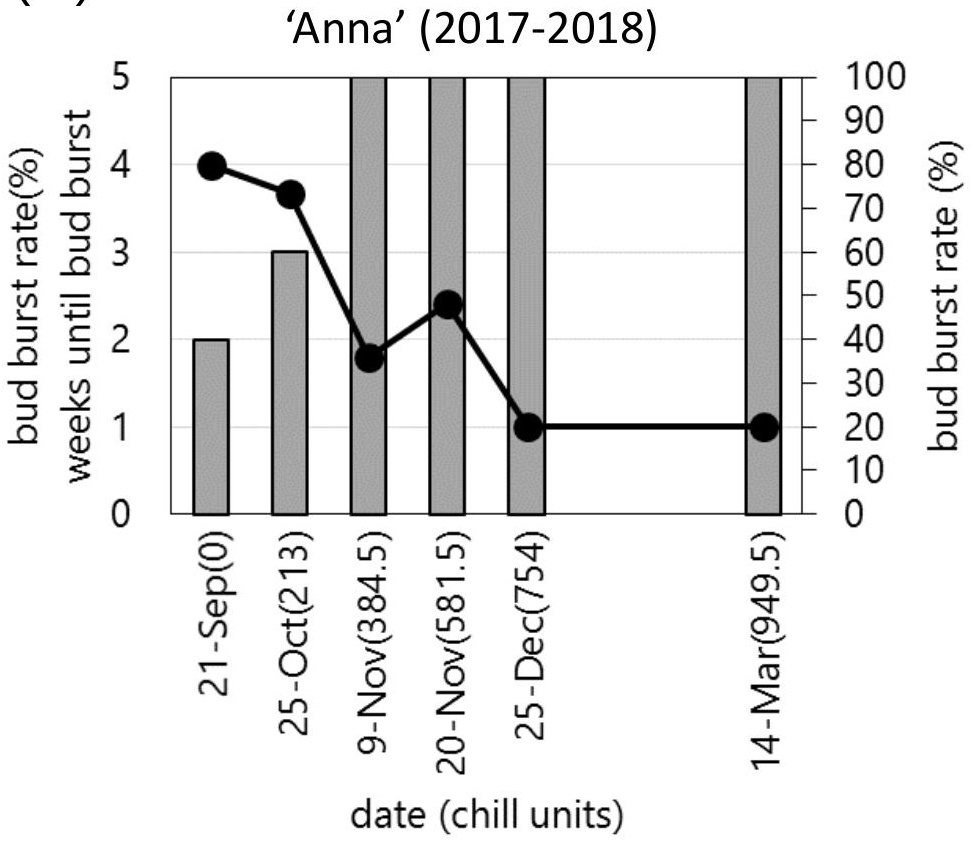


(A)

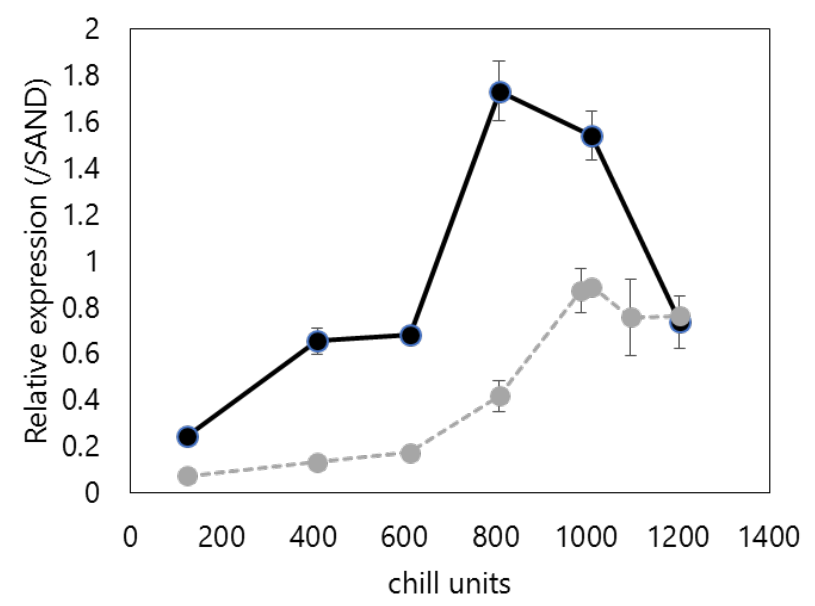

$\longrightarrow$-Anna' ----'Fuji'
(B)

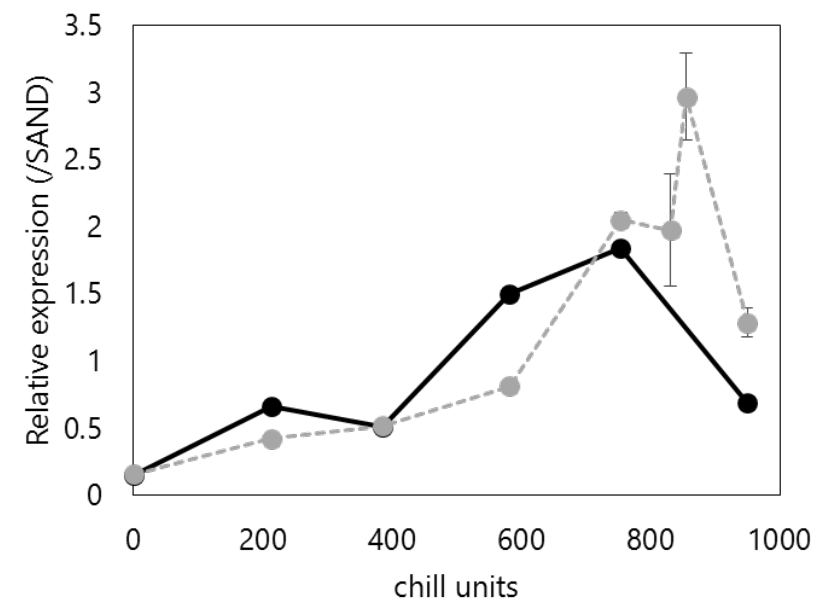

$\longrightarrow$ 'Anna' $\quad$--๑-- 'Tsugaru' 


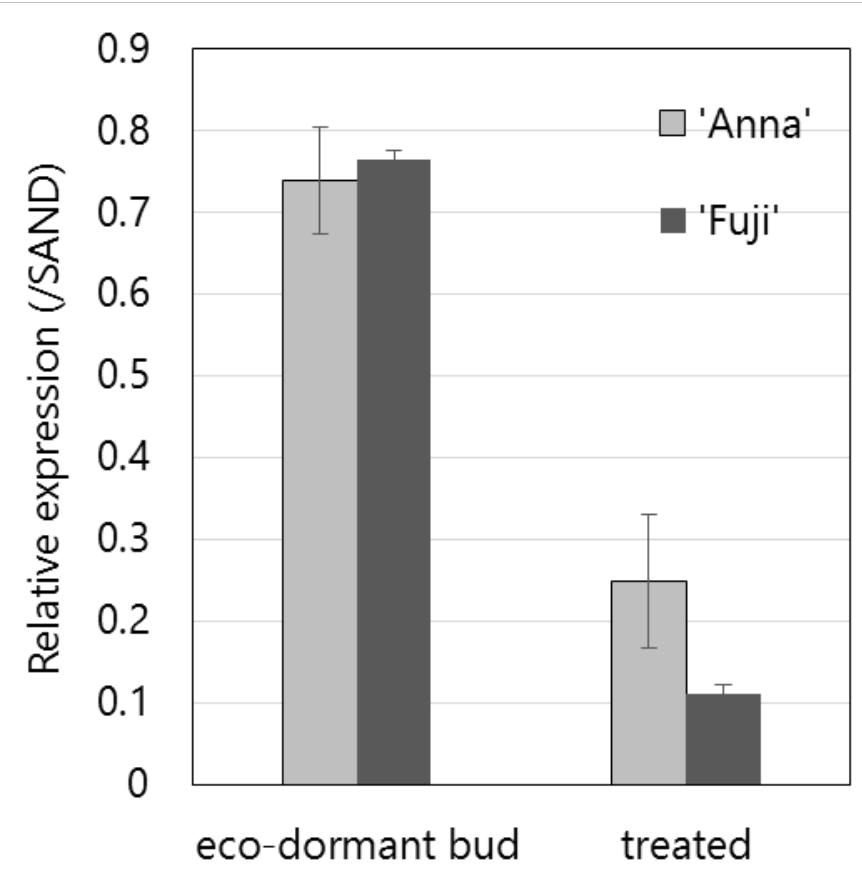



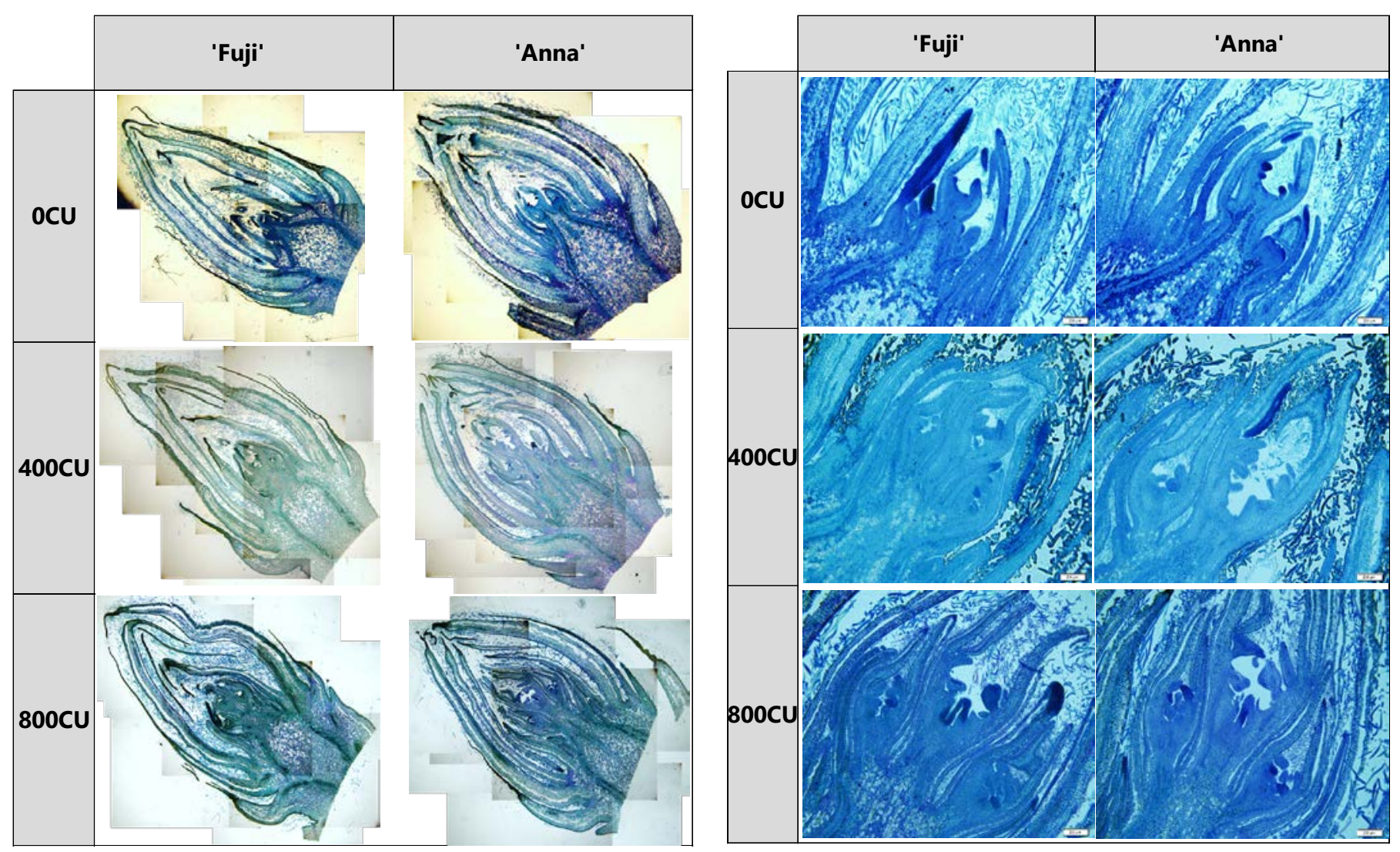

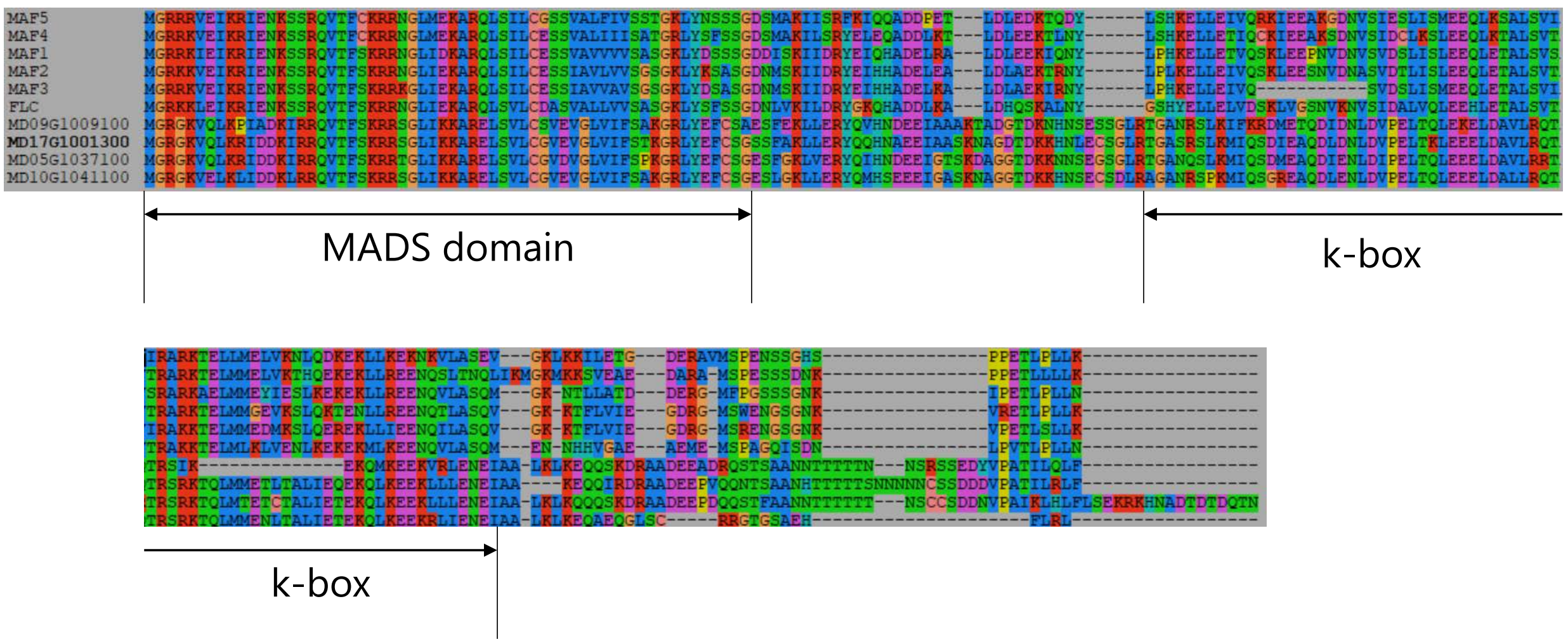

Supplementary Figure 1

Amino acid sequence alignment of FLC homologs of Arabidopsis and apple identified by Takeuchi et al., 2018. 